\title{
A SURDEZ NO CONTEXTO ESCOLAR: DISCUTINDO OS DESAFIOS E ESTRATÉGIAS NO PROCESSO DE ENSINO E APRENDIZAGEM DA INCLUSÃO DE ALUNOS SURDOS NO INSTITUTO FEDERAL CAMPUS VALENÇA
}

\author{
Leíta Dórea Tavares ${ }^{1}$ \\ Marcia Rebeca de Oliveira ${ }^{2}$
}

\section{Resumo}

Devido às políticas públicas de inclusão algumas pessoas com deficiência estão conseguindo frequentar as escolas regulares de ensino. Legalmente os Surdos devem ser incluídos com garantia de acesso, permanência e do direito linguístico respeitado de receber as informações através da Língua Brasileira de Sinais - Libras. Nos Institutos Federais essa inclusão vem acontecendo sistematicamente, então, quais são alguns desafios e estratégias vivenciados no processo de ensino e aprendizagem na inclusão dos alunos Surdos no Instituto Federal campus Valença? O objetivo deste trabalho ao realizar uma pesquisa qualitativa é analisar os desafios e estratégias dos docentes relacionados a possibilitar a acessibilidade, à inclusão e a permanência deles garantindo-lhes um ensino com qualidade. Para isso, foi realizado um estudo descritivo com questionários e entrevistas com ponderações feitas pelos Surdos e por aqueles que efetivamente participam na inclusão destes educandos. Os dados deste trabalho indicam um avanço na tentativa do cumprimento de fornecer uma educação inclusiva com equidade, mas deixa claro há necessidade de que esta Instituição promova a adequação de forma contínua fornecendo a possibilidade de mais formações continuadas para todos no Instituto.

Palavras-chave: Inclusão. Surdos. Permanência. Institutos Federais

\begin{abstract}
Due to public inclusion policies, some people with disabilities are managing to attend regular schools of education. Legally the Deaf should be included with guaranteed access, permanence and the respected linguistic right to receive information through the Brazilian Sign Language - Libras. In the Federal Institutes this inclusion has been happening systematically, so what are some challenges and strategies experienced in the teaching and learning process in the inclusion of Deaf students at the Federal Institute campus Valença? The objective of this work when conducting a qualitative research is to analyze the challenges and strategies of teachers related to enabling their accessibility, inclusion and permanence, guaranteeing them a quality education. For this, a descriptive study was carried out with questionnaires and interviews with weightings made by the Deaf and by those who effectively participate in the inclusion of these students. The data of this work indicate an advance in the attempt to fulfill to provide an inclusive education with equity, but it makes clear the necessity that this Institution promotes the adaptation in a continuous way providing the possibility of more continuous training for all in the Institute.
\end{abstract}

Keywords: Inclusion. Deaf. Permanece. Federal Institutes.

\footnotetext{
1 Mestra em Ciências da Educação pela Faculdade Interamericana de Ciências Sociais (FICS). Docente pela Secretaria Municipal de São Sebastião do Passé. Email: leitadores@yahoo.com.br

2 Doutoranda em Ciências da Educação pela Faculdade Interamericana de Ciências Sociais (FICS) Mestra em Ciências da Educação pela Faculdade Interamericana de Ciências Sociais (FICS). Especialista em Tecnologias Digitais Aplicadas a Educação (Uniasselvi). Especialista em Educação Inclusiva (IFEB). Especialista no Ensino de Libras(IFEB). Especialista em Comunicação Alternativa e Tecnologias Assistivas( SARTRE). Graduada em Licenciatura em Letras/Libras (UFSC). Docente do Instituto Federal da Bahia campus Valença. Coordenadora do Núcleo de Atendimento às Pessoas com Necessidades Específicas. Email: marciarebeca@ifba.edu.br
} 


\section{Introdução}

Socialmente algumas pessoas que se consideram típicas por aparentemente não demonstrarem nenhuma deficiência têm grandes dificuldades em conviver com o diferente e a diferença, sejam estas físicas, psíquicas ou sensoriais, assim o indivíduo não pertencente a classe de normalização, tem a sua identidade social reduzida ficando estigmatizado. Os paradigmas do processo histórico sobre a vivência das pessoas com deficiências são de rejeição e tentativas de exterminação. Enquanto utilizavam a caridade para justificar os atos humanos estendidos a eles, direitos imprescindíveis como a Educação Ihes eram cerceados:

Os indivíduos com deficiências, vistos como "doentes" e incapazes, sempre estiveram em situação de maior desvantagem, ocupando, no imaginário coletivo, a posição de alvos da caridade popular e da assistência social, e não de sujeitos de direitos sociais, entre os quais se inclui o direito à educação (DNEEEB, 2001, p.19)

A estrutura social preconceituosa, sempre oprimiu, negligenciou e os marginalizou, permitindo que vivessem em diferentes momentos, como a exclusão, a segregação, a integração e agora, a inclusão. A figura a seguir, retrata esses momentos históricos:

Figura 1 - A exclusão, segregação, integração e a inclusão

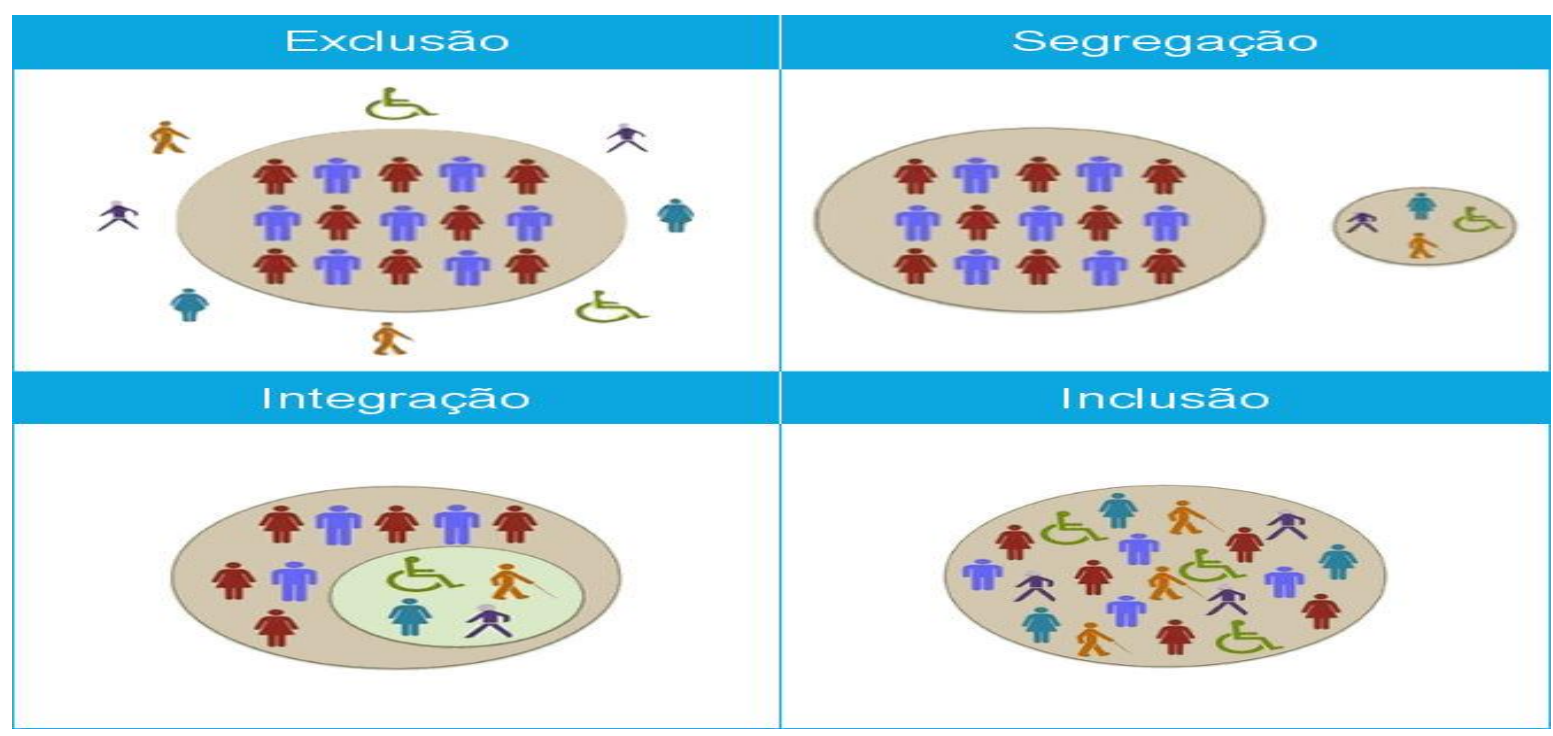

Fonte: Imagens google. https://www.cloudcoaching.com.br/o-que-torna-uma-empresa-inclusiva/

- Mesmo depois de diversas leis sancionadas, ponderar sobre os acontecimentos na vida socioeducacional das pessoas com deficiência pode ajudar a entender a importância da valorização da inclusão escolar. 


\title{
Conceitos de Educação Especial e Inclusiva
}

A educação especial se ocupa diretamente ao atendimento do educando com deficiência no campo da aprendizagem, tanto que há uma declaração que destaca:

\begin{abstract}
Por educação especial, modalidade da educação escolar, entende-se um processo educacional definido por uma proposta pedagógica que assegure recursos e serviços educacionais especiais, organizados institucionalmente para apoiar, complementar, suplementar e, em alguns casos, substituir os serviços educacionais comuns, de modo a garantir a educação escolar e promover o desenvolvimento das potencialidades dos educandos que apresentam necessidades educacionais especiais, em todas as etapas e modalidades da educação básica (BRASIL, 2001 p.1).
\end{abstract}

Como o foco da educação especial é específico para assisti-los e acolhê-los, a proposta da educação inclusiva se fez presente no âmbito educacional com a intenção de englobar uma boa educação para todos incondicionalmente, pois "na inclusão, as pessoas com deficiência estudam na escola que frequentaria se não fossem deficientes" (SASSAKI, 1998, p.8). O texto de Salamanca coaduna com essa possibilidade ao dizer que:

Os sujeitos da inclusão são todos: os que nunca estiveram em escolas, os que lá estão e experimentam discriminações, os que não recebem as respostas educativas que atendam às suas necessidades, os que enfrentam barreiras para a aprendizagem e para a participação, os que são vítimas das práticas elitistas e injustas de nossa sociedade, os que apresentam condutas típicas de síndromes neurológicas, psiquiátricas ou com quadros psicológicos graves(BRASIL, 1994, p. 48).

No decorrer do tempo, ocorreram muitas mudanças das nomenclaturas que categorizava e rotulavam os atípicos, e "falava-se em excepcionais, depois em deficientes, mais adiante em portadores de deficiência, em portadores de necessidades especiais e portadores de necessidades educativas especiais" (MIRANDA, 1999, p.79). Atualmente a Lei oㅜ 13.146, de 6 de julho de 2015, atualiza a nomenclatura correta para pessoa com deficiência, objetivando assim que não se analise apenas a incapacidade que a deficiência traz, antes, as possibilidades que a pessoa tem. A inclusão escolar, mas do que se atentar as deficiências percebidas pelos olhos, atenderia as sentidas na alma.

\section{Inclusão Escolar de Surdos nos Institutos Federais}

A prática da diversidade tem obtido alguns avanços quando executam as leis e politicas públicas focadas na inserção de todos, sem distinção de condições linguísticas, sensoriais, cognitivas, físicas, emocionais, étnicas, socioeconômicas. 
Adentrar a sala de aula não é garantia de aprendizagem se não existirem metodologias diferenciadas adaptadas às especificidades de cada aluno. Para que isso ocorra como um processo de construção gradativo, deve-se prezar "as atitudes dinâmicas, lúdicas, abrangentes, que se distanciem do limitado, do separatista, atitudes voltadas para uma escola cidadã, livre de preconceitos" (SOUZA FREIRE, 2012, p. 4).

Amplia o entendimento desse processo ao dizer que a:

Base Nacional Comum Curricular é um grande avanço para a educação brasileira, pois abre oportunidades para uma educação mais inclusiva, que parta do olhar para 0 aluno e suas singularidades. Ela amplia as possibilidades para que as escolas busquem novas alternativas para ensinar a todos. Sendo assim, dialoga com os princípios do Desenho Universal para a Aprendizagem (DUA), que são: Proporcionar diversos meios para a aprendizagem, proporcionar diferentes formas para expressão do que foi aprendido e manter a motivação e permanência dos estudantes (SILVA FERRARESI, 2017 p.1)

A Resolução CNE/CEB $n^{\circ}$ 2/2001, determinou que os sistemas de ensino deveriam inscrever todos os educandos, garantindo um ensino de qualidade, por isso, muitos surdos estão estudando nos IFs.

As instituições federais de ensino devem garantir, obrigatoriamente, às pessoas surdas acesso à comunicação, à informação e à educação nos processos seletivos, nas atividades e nos conteúdos curriculares desenvolvidos em todos os níveis, etapas e modalidades de educação, desde a educação infantil até à superior (BRASIL, 2005 par.4)

\section{Abordagens Sobre a Surdez e a Prática Docente}

A oralidade permite que o indivíduo se expresse, mas quando há algum impedimento que esse processo natural através do som ocorra, podemos denominar a pessoa como surda. Pode-se definir surdez como "enfraquecimento ou abolição do sentido da audição" (FERREIRA, 2001, p. 694), ela pode ser detectada através de um exame conhecido como audiometria que possibilita determinar a integridade ou defeitos no sistema auditivo.

A comunicação verbal é de extrema importância, mas ela não se da apenas pela audição, é possível se comunicar através da escrita, de forma não verbal, por mímicas, gestos e também pelas mãos como é o caso dos surdos e ouvintes que utilizam a Libras para se comunicarem.

Por ser um canal comunicativo diferente das línguas orais-auditivas, as Línguas de Sinais se dão através do canal viso espacial, onde os sinais são articulados essencialmente pelas mãos e percebidos através da visão. Para 
Fernandes (1998, p.2) ela "é uma língua natural, com organização em todos os níveis gramaticais, prestando-se às mesmas funções das línguas orais" possibilitando o desenvolvimento cognitivo da pessoa surda mesmo sem o uso do canal auditivo. Outra forma que eles podem se comunicar é através da Língua Portuguesa escrita, sendo que, ela e a Libras têm estruturas de construção gramaticais diferenciadas, quer dizer que

Para estruturar os significados lexicais e gramaticais, enquanto a língua portuguesa faz uso do meio acústico, a Libras utiliza de mecanismos espaciais, recursos de repetição, expressões faciais e outros itens lexicais necessários (SILVA e NOGUEIRA, 2014 p. 9).

Existem duas abordagens sobre o conceito de surdez, a primeira é a visão clínica patológica, que determina para eles uma deficiência impeditiva sensorial que precisa ser curada, e a segunda é a sócio antropológica que descreve a necessidade de levar em consideração o contexto sociocultural desse povo. O Surdo não faz parte de uma raça distinta da sociedade ou de sua família ouvinte, pois:

O objetivo de considerar, no estudo da problemática do surdo, a questão cultural não é o de incentivar a criação de grupos minoritários à margem da sociedade, mas justamente o contrário, ou seja, o de considerar a diferenciação linguística como necessária para possibilitar o desenvolvimento normal da cognição, da subjetividade, da expressividade e da cidadania da pessoa surda (SÁ, 1999, p. 157158).

Toda falta física tem sua particularidade, mas a surdez ganha um agravante maior devido à impossibilidade da comunicação quando não se sabe a Língua de Sinais. Uma parte significativa do contexto histórico mudou o rumo educacional, da educação dos surdos, no congresso em Milão em 1880, quando o oralismo foi instituído como forma padrão a ser aplicada. A possibilidade de utilizar a Língua de Sinais para a comunicação foi banida e as resoluções daquela época comprovam para elevação da língua oral como elemento do para aquisição ao conhecimento, e:

Nenhum outro evento na história de surdos teve um impacto maior na educação de povos surdos como este que provocou uma turbulência séria na educação, que arrasou por mais de cem anos nos quais os sujeitos surdos ficaram subjugados às práticas ouvintistas, tendo que abandonar sua cultura, a sua identidade surda e se submeteram a uma 'etnocêntrica ouvintista', tendo de imitá-los (STROBEL; PERLIN, 2008, p. 6).

Os discursos patológicos sobre a importância da cura da surdez alastraramse pelas instituições educacionais. Aos surdos eram cobradas a fala e a leitura orofacial, cerceando-se o direito social de serem surdos. 
Depois de quase um século com o método oralista fracassando, um grande estudioso chamado Willian Stokoe, criou a comunicação total que possibilitava o acesso à linguagem por meio da leitura labial, mímicas, pantomima, da amplificação dos sons, do alfabeto manual e dos sinais visando o desenvolvimento da linguagem. Apesar dos grandes avanços, esse preceito teve algumas inconsistências, pois "nem os sinais nem as palavras faladas podiam ser compreendidos plenamente por si sós" (CAPOVILLA, 2000, p. 109), gerando assim algumas distorções na comunicação.

Mesmo com a melhoria do processo educacional dos surdos, com o decorrer dos tempos outros linguistas disseminaram a importância de uma nova filosofia educacional chamada bilinguismo. No Brasil, ela oportunizava ao surdo seu desenvolvimento cultural, social, e identitário, excluindo a obrigatoriedade do desenvolvimento da fala e "o bilinguismo tem como pressuposto básico que o surdo deve adquirir como língua materna a língua de sinais, que é considerada sua língua natural, e como segunda língua, a língua oficial de seu país" (GOLDFELD, 1997, p. 42). A utilização educacional bilíngue gerou um ganho fenomenal linguístico e cultural para eles.

Atualmente no Brasil, esses métodos ainda são utilizados, contudo para ensinar de forma adequada aos surdos, o professor precisa de uma imersão cultural e linguística sobre eles. Vale destacar que:

A formação do professor deve ser um processo contínuo que perpassa sua
prática com alunos, a partir do trabalho transdisciplinar com uma equipe
permanente de apoio [...] não se trata apenas de incluir um aluno, mas de
repensar os contornos da escola e a que tipo de educação estes
profissionais têm se dedicado (PAULON, 2005, p.24).

Ao refletir sobre esse processo inclusivo, alguns desafios educacionais são encontrados para mitigar os efeitos negativos em prover-lhes um ensino adequado que respeite a diversidade cultural e linguística, como a falta do conhecimento da Língua de Sinais pelos professores, a escassez de material didático e de apoio pedagógico específico para cada componente curricular, e, as vezes, a falta ou condições de trabalho inadequada para os intérpretes de Libras.

Em contrapartida com o objetivo de garantir um ensino com excelência e acessibilidade pedagógica, dá-se a sugestão de utilizar a:

[...] contação de história ou estória, jogos educativos, envolvimento da cultura artística, cultura visual, desenvolvimento da criatividade plástica, visual e infantil das artes visuais, utilização da linguagem de Sign Writing 
(escrita de sinais) na informática, recursos visuais, sua pedagogia crítica e suas ferramentas e práticas, concepção do mundo através da subjetividade e objetividade com as experiências visuais (CAMPELLO, 2007, p. 129).

Por serem discentes aprendizes visuais pode-se citar componentes fundamentais para o processo de ensino e aprendizagem, frisando a utilização de elementos imagéticos como "uma maquete, um desenho, um mapa, um gráfico, uma fotografia, um vídeo, um pequeno trecho de filme" (LACERDA e SANTOS, 2013, p.188). Outras estratégias como apoio pedagógico são os filmes, textos de literatura, mensagens trocadas no Whatzapp, textos de redes sociais, cartas, cardápios, receitas de algo que o discente goste, manchetes de jornais, programas televisivos, programas no youtube, histórias de vida, tudo isso em um contexto educacional inclusivo que vise evitar todas as tentativas de homogeneização ou normalização, mas o desenvolvimento cognitivo, educacional, social, e a autonomia dos discentes surdos.

\section{Considerações}

Existe a inclusão dos surdos no IFBA campus Valença, mas apesar de ter uma gama de profissionais competentes nas suas respectivas áreas, por não terem uma formação continuada visando o ensino as pessoas surdas, a falta de atenção ao aluno, a despreparação para articular aulas visuais e o sentimento de frustação por não saber o que fazer são desafios evidentes.

Foi possível perceber as estratégias da utilização de recursos visuais, a adaptação do ritmo das aulas; as mídias visuais, o olhar atento para o estudante surdo; o dialogo humanizado ao perguntar se ele está entendendo os conteúdos com a disposição de lhes ensinar novamente, as avaliações diferenciadas e o uso de aplicativos.

Existe a necessidade de formação continuada para os docentes, pois o processo inclusivo precisa harmonizar teoria e prática derrubando as barreiras arquitetônicas e atitudinais, pois todos são responsáveis por promover uma educação de excelência. O Instituto Federal campus Valença muito tem a progredir nessa inclusão, mas já dá passos necessários para que ela aconteça. A inclusão escolar é um direito de todos, por isso, urge que politicas públicas continuem sendo efetivadas, que Libras continue sendo aprendida, que as barreiras atitudinais com relação ao respeito da aceitação dos surdos sejam derrubadas e que todos tenham 
direito ao acesso, permanência e uma educação com qualidade e equidade em qualquer ambiente educacional inclusive nos Institutos Federais.

\section{Referências}

ALVES, F. Inclusão: muitos olhares, vários caminhos e um grande desafio. Rio de Janeiro: Wak, 2009.

BRASIL. Declaração de Salamanca: Sobre Princípios, Políticas e Práticas na Área das Necessidades Educativas Especiais, Salamanca-Espanha, 1994

BRASIL. Decreto Federal n 5.626 de 22 de dezembro de 2005. Regulamenta a Lei no 10.436, de 24 de abril de 2002, que dispõe sobre a Língua Brasileira de Sinais: Libras, e o art. 18 da Lei no 10.098, de 19 de dezembro de 2000. BrasíliaDF: Diário Oficial da União, 2005

BRASIL. Lei de Diretrizes Nacionais para a Educação Especial na Educação Básica. Brasília : MEC / SEF/SEESP, 2001.

BRASIL, Ministério da Educação e do Desporto. Política Nacional de Educação Especial. Brasília, MEC/SEESP, 1994.

CAMPELLO, A. R. S. Pedagogia Visual: Sinal na Educação dos Surdos. In: Quadros, R. M. de.; Perlin, G. (orgs). Estudos Surdos II. Petrópolis: Arara Azul, 2007.

CNE. CEB. Resolução n. 2, de 11 de setembro de 2001, que institui as Diretrizes Nacionais para a Educação Especial na Educação Básica. Brasília: 2001

CAPOVILLA, F. C. Filosofias educacionais em relação ao surdo: do oralismo à comunicação total ao bilinguismo. [s.l.]: Revista Brasileira de Educação Especial, 2000.

FERNANDES, S. Surdez e linguagem: é possível o diálogo entre as diferenças? Dissertação de Mestrado. Curitiba: UFPR, 1998.

FERREIRA, A. B. H. Miniaurélio século XXI: o miniaurélio da língua portuguesa. 5. ed. ver. ampliada. Rio de Janeiro: Nova Fronteira, 2001.

FREIRE, P. Política e educação. São Paulo: Cortez Editora, 1993.

FREIRE, P. Pedagogia do oprimido. 17. ed. Rio de Janeiro: Paz e Terra, 1987.

GOLDFELD, M. A criança surda. São Paulo: Plexus, 1997.

LACERDA, C. B. F; SANTOS, L.F. Tenho um aluno surdo. E agora? : Introdução à Libras e educação de surdos. São Carlos: EdUFScar, 2013. 
Lei no 13.146, de 06 de julho de 2015. Institui a Lei Brasileira de Inclusão da Pessoa com Deficiência (Estatuto da Pessoa com Deficiência). Disponível em: . Acesso em: 21 abr. 2019.

Ministério da Educação e Cultura. Secretaria de Educação Especial. Saberes e práticas da inclusão: desenvolvendo competências para 0 atendimento às necessidades educacionais de alunos surdos. Brasília: MEC/SEESP, 2006. Disponível em: . Acesso em: 20 mar. 2019

MIRANDA, T. G. A Educação do Deficiente Mental e a Teoria Histórico-cultural: Pontos de Aproximação. In: A Educação do Deficiente Mental: construindo um espaço dialógico de elaboração conceitual. São Paulo: USP, 1999.

PAULON, S. M; LUCCA, L. B. F; PINHO, G. S. Documento subsidiário da política de inclusão Brasília: Ministério da Educação, Secretaria de Educação Especial, 2005.

PERLIN,G. A cultura surda e os intérpretes de Língua de Sinais. Campinas: ETD Educação temática digital, 2006.

SÁ, N.R.L. A Educação dos surdos: a caminho do bilingüismo. Niterói: EDUFF, 1999.

SEVERINO, A. J. A busca do sentido na formação humana: tarefa da filosofia da educação. São Paulo: Educação e Pesquisa, 2006.

SEVERINO, A. Educação, trabalho e cidadania: a educação brasileira e o desafio da formação humana no atual cenário histórico. São Paulo: São Paulo em perspectiva,.2000.

SASSAKI, R. K. Entrevista. In: Revista Integração, Brasília, 1998.

SILVA FERRARES I. Inclusão na escola 2017 <http://inclusaonaescola.com.br/ascontribuicoes-da-bncc-para-uma-educacao-inclusiva/> Acesso em 19 de mar 2019

SKLIAR, C. (org.) Educação e exclusão: Abordagens Socioantropológicas em Educação Especial. Porto Alegre, Mediação, 1997.

SILVA, D. L. Práticas Pedagógicas na Escola Inclusiva: Adaptação Curricular Programa De Desenvolvimento Educacional - PDE - Núcleo Regional de Ensino de Jacarezinho. Jacarezinho: Cadernos PDE 2014.

SOUZA FREIRE, S. Inclusão escolar: práticas pedagógicas para uma educação inclusiva.[s.I]:[s.e], 2012.

STROBEL, K. L. Surdos: vestígios culturais não registrados na história. Dissertação de mestrado. Santa Catarina: UFSC, 2006 